\title{
Globalizando la acción social
}

\author{
Carolina Quinteros
}

En el mes de mayo del año 2001, una de las más importantes organizaciones antisweatshop' en los EEUU, el Comité Nacional Laboral (NLC) acusó a varias fábricas de maquila de ropa en El Salvador de cometer violaciones a los derechos laborales. La Asociación Salvadoreña de la Industria de la Confección (ASIC) contestó: "Si tienen pruebas, que las muestren". Y eso precisamente fue lo que hizo el CNL. Para el mes de junio, lanzó públicamente un documento con información de violaciones laborales en al menos 10 fábricas que cosían ropa para reconocidas marcas de ropa estadounidenses. Con independencia de qué tan ciertas eran esas aseveraciones o de qué tan profunda la investigación que las sustentó, lo cierto es que el documento desató revuelo en el sector de maquiladores del país, que no dudaron en acusar al CNL de boicotear una posible renegociación del acuerdo de la Iniciativa de la Cuenca del Caribe (ICC) ${ }^{2}$.

La preocupación fue tanta, que el Ministro de Trabajo en persona, salió en defensa de los maquiladores y anunció medidas para mejorar la inspección del Ministerio de Trabajo. Él mismo inició una serie de inspecciones en distintas empresas del país y en medio de un despliegue frente a los medios, procedía a revisar las instalaciones y a hacer entrevistas con las trabajadoras. En una de estas fábricas y frente a la prensa, preguntó a una trabajadora sobre su situación laboral. Lejos de sentirse intimidada, la trabajadora manifestó frente a la cámara, que ella era parte de un grupo de personas que recientemente había sido despedido de esta empresa por intentar formar un sindicato y que las 
violaciones a los derechos laborales en esa fábrica eran bastante frecuentes.

Según la nota de El Diario de Hoy del 5 de junio del 2001, la fábrica Han Chan, donde laboraba esta trabajadora, había despedido a 17 personas que habían intentado formar un sindicato y que habían realizado quejas por algunos problemas dentro de la empresa. El despido había preocupado a uno de los clientes de la empresa: la marca de ropa Phillips Van Heusen (PVH), según se sabe, por entrevistas a los trabajadores de esta fábrica. Este cliente había llamado a la ASIC para pedirle su colaboración en la solución a esta violación a los derechos laborales. La ASIC, a su vez había llamado al Ministerio de Trabajo y así se involucró éste también, para solucionar los despidos ilegales cometidos en contra de los sindicalistas y arreglar su regreso a la empresa. Los sindicalistas regresaron a la empresa, reorganizaron su sindicato y para el mes de julio del 2002, según manifiestan sus directivos, mantienen cerca de 200 afiliados. Además, la fábrica ha experimentado modificaciones interesantes: reciben la visita periódica de una persona de PVH que se encarga de vigilar cumplimientos a la ley nacional y al código de conducta de esa compañía. Esta persona ha implementado capacitaciones sobre derechos humanos y si bien, siguen habiendo críticas al manejo de la ley laboral en esta empresa, las trabajadoras han visto reducir en gran medida los antiguos problemas de discriminación y maltrato.

El caso no fue único. Un par de semanas antes, otro grupo de trabajadores había sido despedido por el mismo motivo de Amitex, otra maquila de capital asiático, ubicada asimismo en la Zona Franca de San Marcos (Co Latino, 11 de junio del 2001). El regreso de estas personas a sus puestos de trabajo, había sido también motivado por uno de sus clientes, que en este caso, elaboraba ropa por encargo de una universidad estadounidense, cuyos estudiantes demandan que las ropas con el logo de su Alma Mater, fueran claboradas "sin explotación". Los estudiantes, a través del Consorcio de Derechos Laborales (WRC por sus siglas en inglés), demandaron a esta empresa ponerse en cumplimiento y llevar a la fábrica nuevamente, aquellas personas que hubieran sido despedidas por razones sindicales. Aquí, las mejoras han sido sumamente modestas (si es que ha habido alguna) y aún hay quejas de violaciones graves al derechos de libertad de asociación, pero al menos nos muestra un caso más en que una maquila reconoce que 
ha violado la ley y que, presionada por sus clientes, toma acciones para corregirse.

Pero aún hay más. Años antes, El Salvador también presenció cómo algunas marcas de ropa de los EEUU se involucraron en la solución de violaciones a la libertad de organización sindical cometidas por empresarios ubicados en El Salvador. Liz Claiborne se involucró en la recontratación de trabajadoras sindicalistas de una fábrica de capital coreano en 1999 y lo mismo había sucedido con Gap en 1996, en el famoso caso Mandarin (GMIES, 2002). De hecho, y siguiendo el tema de libertad de organización sindical, para el 2001 solamente había cuatro sindicatos independientes ${ }^{3}$ en maquilas salvadoreñas y los cuatro habían sido formados luego de la intervención de los clientes de las maquilas de donde fueron originalmente despedidos.

Fuera de El Salvador también abundan los casos en que las compañías transnacionales se han mostrado más preocupados que los gobiernos en hacer cumplir la normativa laboral. En Guatemala, en 1998, pese a la resistencia del gobierno y de la misma fábrica, un sindicato logra firmar el primer y único (hasta julio del 2002) contrato colectivo en fábricas maquiladoras ubicadas en Guatenala, luego de la intervención de PVH a favor del sindicato. En el 2001, la compañía Nike se involucró de lleno en diseñar un plan remedial para uno de sus contratistas en México (la fábrica Kuk Dong), que había violado el derecho en las trabajadoras a organizarse en un sindicato independiente y en enero del 2002 en República Dominicana, Nike y Reebok trabajaron en conjunto para resolver otras violaciones a la libertad de organización en la fábrica $\mathrm{BJ} \& \mathrm{~B}$.

Pero los ejemplos no cesan allí. El año 2000, la compañía Chiquita firma un acuerdo con la sindicatos bananeros de Latinoamérica, en el cual se compromete a que los sindicatos mismos vigilen el cumplimiento del código de conducta de la compañía en todas sus fincas y en el caso de la industria de flores, algunos supermercados suizos y alemanes han comenzado a vender flores certificadas de haber sido elaboradas bajo normas ética de respeto a derechos laborales y en paises productores tales como Zimbabwe, Colombia y Ecuador (Frank, 2000). En el mes de julio, en una nota aparecida en la Prensa Gráfica, se supo que la ciudad de San Francisco está propugnando vender solamente café cosechado y sembrado bajo iniciativas de comercio justo y 
la cadena estadounidense de cafeterías Starbucks, ya ha implementado desde hace unos años, el café de comercio justo, especialmente sembrado y cosechado en Guatemala.

Probablemente, el caso Han Chan, aunque recibió la atención de los medios por un par de días, pasó inadvertido para la mayoría de salvadoreños y salvadoreñas, incluso para quienes trabajan en la defensa de los derechos laborales. Sin embargo, en realidad, constituye un ejemplo más de la nueva forma de hacer las cosas en el movimiento laboral y una expresión de un modelo de acción laboral emergente en los países llamados del Sur. Este modelo emergente, constituiría una respuesta completamente insertada y congruente en el mundo globalizado, la cual por supuesto, no está libre de contradicciones.

\section{El modelo emergente de acción laboral}

Las acciones laborales en las maquilas de ropa presentan varias características novedosas. Una de ellas se relaciona con la posibilidad de relocalizar los espacios de la acción. Las protestas no se hacen solamente en El Salvador, México, Guatemala, o algún otro país productor, sino que se incluyen las acciones frente a las tiendas distribuidoras de las marcas clientas de las fábricas locales, protestas en los centros comerciales de los EEUU, Canadá y Europa; visitas al Congreso de los EEUU y presencia en medios de aquellos países. El caso de Mandarin International en 1995, además de las protestas en las afueras de la zona franca de San Marcos, incluyó una serie de protestas en las tiendas de Gap en los EEUU y Canadá. De manera similar, los activistas que descubren violaciones laborales en empresas ubicadas en algún país del Sur, inmediatamente urgen cartas de protesta o acciones frente a las sedes de las empresas clientas. Benetton, Nike, Adidas y Gap, entre otras, no se han escapado de este tipo de protestas y ni siquiera las estrellas del deporte Michael Jordan y Tiger Woods han podido eludir preguntas comprometedoras respecto a las fábricas en que se producen los bienes que promueven (MSM, 2001).

Las redes de activistas antisweatshop, igual que los activistas de derechos humanos, derechos de las mujeres, ecologistas, entre otros, se valen de mecanismos no institucionales para influir en la toma de decisiones. Dentro de estos mecanismos, el uso de información proveniente de actores de los países donde se desata el conflicto, es vital 
para provocar la preocupación de la sociedad sobre un tema en particular. La información se procesa de manera tal que genere valores y símbolos capaces de penetrar en el imaginario colectivo del público al que se quiere convocar y movilizar (Keck y Sikknk, 1999).

De esta manera, una de las primeras grandes campañas sobre la maquila centroamericana, toma el testimonio de una joven menor de edad trabajadora de las maquilas hondureñas y lo convierte en el símbolo del maltrato que sobre las trabajadoras comete una de una de las prestigiosas marcas de ropa de los EE.UU. (Liz Claiborne, en el caso de Lesly Rodríguez en 1994). La campaña, que intentaba denunciar malas condiciones de trabajo en general, se centra en la denuncia del trabajo de menores y lo presenta, además, como un caso de explotación laboral de niñas, tema para el cual, el consumidor o consumidora estadounidense es especialmente sensible.

La coordinación entre los activistas en el Norte y los actores centroamericanos, no está exenta de dificultades. Sin embargo, las redes sobre los "talleres de sudor" son diferentes a otras redes de activistas internacionales. En este caso, se trata de un problema de origen laboral, en el que el conflicto clasista permanece y donde lo que se discute en última instancia, es el reparto de los beneficios de una actividad económica, dentro de una relación capital-trabajo. Los trabajadores y trabajadoras textiles del Norte salieron desfavorecidas de la segmentación geográfica de la producción y los primeros activistas del Norte tenían un discurso de tono proteccionista. Actualmente el discurso está cambiado a favor de introducir al Sur en el debate y actores no sindicales ni laborales (como los estudiantes universitarios) han entrado a formar parte del movimiento, pero es previsible que algunos activistas antisweatshop no resulten completamente desinteresados y que se siga manteniendo un tono proteccionista en la supuesta solidaridad con los y las trabajadoras en el Sur.

Difícilmente la producción de ropa va a regresar a los EEUU y esto parece ser una tendencia ya asumida por los sindicatos de ese país. Sin embargo, sí es posible imaginar que estos sindicatos intentarán disuadir a que nuevas industrias salgan de allá masivamente, tal y como las dedicadas a la elaboración y tratamiento de telas, que hasta ahora había estado protegida por los acuerdos de la ICC. De hecho, los sindicatos estadounidenses ya se han estado movilizando para detener la posibilidad de que los acuerdos de la ICC dejen al descubierto 
estas industrias y en muchas de sus acciones y discursos puede evidenciarse una tendencia más bien proteccionista.

Además de estas tensiones Norte-Sur dentro del movimiento activista, otra novedad de este modelo emergente de acción social, la presenta el hecho de que los actores involucrados no son los típicos actores tradicionales de la acción laboral: Estado, sindicato y empresa. Hay una participación creciente de organizaciones no gubernamentales (ONG) nacionales y extranjeras y sindicatos nacionales e internacionales.

Dentro de las organizaciones no sindicales, las más activas de la región resultan ser las de mujeres y las de derechos humanos. Particularmente, las organizaciones de mujeres han comenzado a realizar acciones directas de defensa de los derechos laborales y a aplicar mecanismos alternativos de organización de las trabajadoras de las maquilas. Los énfasis han sido puestos en derechos y situaciones que no forman parte de las reivindicaciones sindicales que han sido tradicionales en la región: protección a la maternidad, acoso sexual, trabajo de menores, empoderamiento de las mujeres dentro de las organizaciones, doble jornada de las mujeres trabajadoras, entre otros.

Para estas organizaciones, la maquila presenta un nuevo proletariado que debe ser atendido tomando en cuenta no sólo los problemas que comparte con los obreros industriales, sino las particularidades de su género ${ }^{+}$. En Honduras y Nicaragua, se han experimentado, además, nuevas formas de organización para estas trabajadoras, con estructuras menos rígidas que las de los sindicatos y orientadas a la capacitación en materia de derechos laborales y de género. En Nicaragua, a partir de esta nueva forma de convocar a las obreras se propone, además, un estilo alternativo de representación de las mujeres trabajadoras y de defensa de sus derechos laborales, realizado directamente por una organización de mujeres ante el gobierno y los empresarios nacionales. Para éstas entidades, los derechos sindicales no forman parte de su agenda, aunque en Honduras sí han intervenido en más de algún conflicto de carácter colectivo y sindical.

La participación de organizaciones no sindicales en asuntos laborales se realiza en las áreas en que los sindicatos no han podido acceder. Sin embargo, su coexistencia con los sindicatos no es sencilla y en muchos casos ha sido bastante conflictiva. Los sindicatos reclaman la 
usurpación de sus tareas y las ONG, especialmente las feministas, sostienen que las mujeres tienen demandas y dinamicas propias que no necesariamente han sido consideradas por los sindicatos.

Por otro lado, las acciones emprendidas en defensa de derechos de las trabajadoras de la maquila, no necesariamente tienen como blanco al Estado. Como hemos visto al principio del artículo, los blancos de las quejas y a quien se le reclama actuar es a las marcas.

Investigaciones previas (Quinteros, 2001) permiten ver que para todos los países centroamericanos, los actores mantienen serias dudas sobre la capacidad del Estado de defender los derechos laborales, especialmente en lo que corresponde a los derechos colectivos. El ejercicio de la libertad de organización sindical y la negociación colectiva es cada vez más precario y pese al incremento de la actividad reivindicativa sobre este tema y al uso de estrategrias cada vez más sofisticadas, el número de sindicatos activos en la maquila ha disminuido (Cordero, 1999). Frente a estas dificultades los Estados no han respondido a favor de los actores sindicales y ésta parece ser una crítica generalizada en la región.

Entre quienes cuestionan la eficiencia de los Estados, no sólo se encuentran los actores sindicales o laborales. Las mismas empresas transnacionales han expresado sus dudas y optan por mecanismos alternativos de monitoreo en sus fábricas proveedoras. Los empresarios guatemaltecos, por ejemplo, han implementado un sistema de certificación de las maquilas que trabajan en ese país, realizan auditorias laborales alternativas a las del Ministerio de Trabajo y han desarrollado sus propias formas de capacitación en el derecho laboral guatemalteco, traduciéndolas al inglés y al coreano.

Uno de los instrumentos desde los que el Estado ha regulado los derechos laborales son los códigos de trabajo y dentro de los mecanismos para el ejercicio de los mismos están las leyes orgánicas de los ministerios de trabajo, los procedimientos de los tribunales laborales y otras instituciones del Estado. Paralelo al uso de tales mecanismos, en Centroamérica, con excepción de Costa Rica, se estarían utilizando los códigos de conducta corporativos y multisectoriales para llamar la atención de las empresas transnacionales, así como la denuncia frente al público consumidor y el monitoreo privado de las condiciones de trabajo ${ }^{5}$. 
¿Por qué razón los clientes de estas fábricas parecen preocuparse más que nuestro gobierno en hacer cumplir la ley laboral?

\section{Las marcas}

Liz Claiborne, Gap, Phillips Van Heusen, entre otras, son empresas con ventas millonarias en EEUU, Canadá y Europa que basan su éxito comercial, en la promoción, precisamente de la marca. Estas compañias forman parte de un nuevo conjunto de empresas que no se dedican a fabricar la ropa que venden, sino más bien a diseñarla y a comercializarla.

La fabricación se la encargan a otras empresas y así, además de abaratar costos, pueden deslindarse de todos los inconvenientes que tiene la producción de mercancías y dedicarse a donde realmente esta la fuente de sus ingresos: la venta directa al consumidor, ya sea en tiendas de ropa especializada (como las de Nike, Levi's, Gap, etc.) y/o en grandes almacenes (Wall Mart, JC Penney, Sears, etc.). Vale la pena mencionar que Wall Mart es la empresa con mayores ingresos en los EEUU, para el año 2001, según la revista Fortune, por encima de Exxon, General Motors y Ford (Fortune, 2002).

Para comercializar sus productos, esta empresas deben saber presentarlos al consumidor y es aquí donde el mercadeo aconseja explotar la marca como un concepto, en el cual la imagen es lo que cuenta. El Vicepresidente de Marketing de Starbucks, una importante cadena de cafés en los EEUU, dice que "los consumidores no creen verdaderamente que haya una gran diferencia entre los productos y por eso, las marcas deben establecer relaciones emocionales con sus clientes" La marca ya no aparece como un artículo de consumo, sino como una experiencia o un estilo de vida. Nike ha trabajado duro para convertirse en el símbolo del estilo americano de la vida sana y el deporte como modo de destacarse y/o de integración social, Benetton en la imagen de lo alternativo y el "compromiso" con causas tales como la no discriminación racial, Tommy Hilfiger, como expresión de la diversidad racial que compone la nación estadounidense; Adidas, como promotor del fútbol en el mundo, etc.

Aparentemente, en una sociedad de consumo, la gente no compra un producto necesariamente por su utilidad. Lo compra porque el producto lo refiere a una experiencia, a un estilo de vida del cual 
quiere formar parte. La relación con el producto se da a nivel de conceptos abstractos, tales como la vida sana, la rebeldía, la autoafirmación femenina, la pasión por el fútbol, etc. y no necesariamente a través de la parte física del bien. Es bien conocida esa faceta del consumismo de preferir marcas antes que productos y la capacidad que tienen algunas personas (incluso de escasos recursos económicos) de gastarse una pequeña fortuna en artículos que probablemente en nada se diferencian de otros con etiquetas menos conocidas. En nuestro país, en que la falta de ingresos impide estos gastos, se recurre a la piratería de las marcas y no es raro encontrarse con falsificaciones de etiquetas o de sellos de algunas marcas en prendas de ropa elaboradas sin licencia.

En suma, la venta al por menor, es decir, el lugar en que se concentran las ganancias de las empresas de ropa, se basa en la promoción de una imagen de empresa. La imagen es el centro de estas empresas y por supuesto, esto mismo las vuelve vulnerables.

Los activistas laborales en los EEUU han descubierto que una buena forma de involucrar a las grandes compañías en la resolución de problemas en las fábricas maquiladoras, es precisamente, comprometiendo su imagen frente a sus consumidores y afectado sus ventas. En el caso de algunas empresas como Nike, las ventas se redujeron sensiblemente luego de 1995 y los beneficios trimestrales se redujeron en un $70 \%$, hasta 1999 , en que estos rendimiento se recuperaron, pero no como producto de la mejora en las ventas, sino a costa (según la misma empresa) de una reducción de personal y de contratos (Klein, 2001 p. 436).

Luego de 1995, el año en que más protestas aparecieron en los medios estadounidenses, muchas empresas de ropa se sumaron al tema de la responsabilidad social. Crearon o tradujeron códigos de conducta corporativos mediante los cuales todas las empresas con quienes se relacionan a lo largo de su cadena de producción, deben cumplir. A la fecha se han contabilizado más de 125 códigos de conducta a nivel global y cada una de estas empresas tiene (o debería tener), un sistema de monitoreo de los mismos, que en prácticamente ningún caso, pasa por el Estado.

Pero además, se cuenta también con códigos y mecanismo de monitoreo llamados multisectoriales. Los códigos de conducta multisectoriales se refiere a iniciativas tripartitas o cuatripartitas generadas en los países consumidores de los bienes maquilados en el Sur. 
Para EEUU, el primer código multisectorial que surge es el actualmente llamado código de la Fair Labor Association (FLA), avalado por las principales marcas de ropa estadounidense tales como Levi's, Nike, Liz Claibrne, PVH, Adidas, etc. Posteriormente surge la iniciativa SA 8000 cuyo código ha sido elaborado en conjunto por sindicatos internacionales, ONG de derechos humanos (tales como Human Rigths Watch) y sectores empresariales tales como Dole, Avon y Toy Are Us. El código de la iniciativa formada por las organizaciones de estudiantes universitarios y los sindicatos estadounidenses llamado el Workers Rigths Consortium (WRC) aparece después en la escena para involucrar a las empresas que trabajan la ropa de las universidades estadounidenses y finalmente, como una respuesta del sector empresarial más conservador y sectores sindicales vinculados al desaparecido Instituto Americano para el Desarrollo del Sindicalismo Libre.

En suma, la imagen de las marcas, que constituye la piedra angular de las grandes compañías de indumentaria, son asimismo, su Talón de Aquiles que ha sido aprovechado por los activistas laborales alrededor del mundo, para exigirles cuentas sobre el trato que reciben las personas que elaboran sus mercancías. Estas cuentas se rinden a través de instancias no estatales $y$, aunque casi todos los códigos corporativos hacen referencia al cumplimiento de las legislaciones nacionales, lo cierto es que el monitoreo de los mismos y la rendición de cuenta de estas compañías hacia el público consumidor, no se hace por medio de instancias estatales.

\section{El Estado}

Los Estados centroamericanos no se han distinguido por atender los problemas de la clase trabajadora y su trayectoria, más bien, da muestras de poca apertura a la canalización de demandas colectivas, pero en las sociedades actuales y de frente a la globalización, estos Estados pierden aún más capacidad de responder a las demandas de su ciudadanía. Muchas de las funciones que habían sido más o menos realizadas desde los Estados (como el monitoreo de las condiciones de trabajo) se trasladan cada vez más hacia la sociedad civil.

Al menos para algunos casos de fábricas de maquila de ropa, parece más efectivo quejarse ante las empresas que ante los Estados, hacer cabildeo frente al público consumidor que en las oficinas de los minis- 
terios de trabajo. Las trabajadoras de Han Chan, por ejemplo, trasladaron sus denuncias y quejas hacia una compañía, no hacia el Estado. En otros casos, si se recurre a alguna instancia estatal, no es centroamericana y las acciones esperadas son de carácter comercial, es decir, actuando nuevamente en los ámbitos del mercado. Un ejemplo de esto último es el bien documentado poder disuasivo del Sistema General de Preferencias (SGP).

El Sistema Generalizado de Preferencias (SGP) es una concesión del gobierno estadounidense a los países de la Cuenca del Caribe, mediante la cual estos gozarían de preferencias arancelarias a la hora de exportar bienes a los E.EUU. Para poder gozar de estos privilegios, los gobiernos deben mostrar que cumplen con ciertas regulaciones, entre ellas, el respeto a la libertad de organización sindical. Los sindicatos de los EEUU pueden denunciar ante su Congreso que un país no cumple con algunos de estos temas y este país correría el riesgo de ser excluido de esta concesión. Los sindicatos centroamericanos buscan aliados en los sindicatos u otras organizaciones laborales de los EEUU y a través de ellos (especialmente de la America Federation of Labor, AFL-CIO), elevan una denuncia y solicitan la exclusión. A la fecha, ningún país fue sancionado, pero la mera denuncia ha facilitado la resolución de casos de violaciones a derechos laborales, especialmente, el de la libertad de organización. En todos los países centroamericanos se registran exitosos casos de sindicatos legalizados luego de una denuncia sobre el SGP, sin embargo, uno de los ejemplos más interesantes lo constituye el caso de Costa Rica en 1993.

En 1988, los sindicatos costarricenses, presentaron una demanda anta la OIT en contra del Estado costarricense por su política de promoción del solidarismo. Los sindicatos manifestaron que el gobierno confería amplias facultades a las organizaciones solidaristas en materia de ventajas organizativas y de negociación colectiva, que iban en detrimento de las libertades sindicales. El caso fue fallado a favor de los sindicatos costarricenses demandantes. La Comisión de la OIT que realizó la investigación del caso encontró suficientes méritos para señalar al Gobierno costarricense que su legislación en materia laboral reñía con la aplicación del convenio 98 de la OIT y que esperaba que se realizaran las correcciones legales pertinentes para evitar que las asociaciones solidaristas asuman funciones sindicales y para que se garantice la protección sindical (Quesada Arce, 1994). Sin embargo, 
las recomendaciones de la OIT, emitidas en 1991, no fueron atendidas sino hasta después de las denuncias sobre el SGP, en noviembre de 1993.

Para Costa Rica, las denuncias sobre la SGP tuvieron efectos inmediatos sobre la regulación de las relaciones laborales y crearon condiciones favorables para el sindicalismo privado. En primer lugar, el Código de Trabajo tuvo modificaciones interesantes en materia de libertad de organización sindical y negociación colectiva. Para ese año, el código adiciona un capítulo entero (del Artículo 363 al 370) sobre protección de los derechos sindicales, introduciendo la figura del fuero sindical para dirigentes y líderes de sindicatos, que antiguamente no estaba estipulado.

Muchos sindicatos aprovecharon la coyuntura para intensificar sus esfuerzos de organización en el sector. Los diez casos de comités sindicales existentes en el país se desarrollaron justamente en la coyuntura de las denuncias sobre la SGP y los sindicalistas han manifestado que durante ese período disminuyó la represión sindical (Trejos y Mora: 1995).

Ciertamente, las presiones sobre el SGP tuvieron un efecto a favor de la organización sindical en casi todos los países centroamericanos. Para todos, puede notarse que durante los años en que aún se mantenía la presión sobre este tema, se lograron organizar más sindicatos.

El decrecimiento de un papel activo del Estado, unida a la creciente interpelación de actores empresariales y el uso de mecanismos no estatales o al menos, no dentro de los Estados centroamericanos, para la defensa de los derechos de los y las trabajadoras, cuestiona en el fondo, la forma en que está siendo administrada la ciudadanía social en las sociedades centroamericanas. Si el Estado es aún menos capaz de generar bienestar y de resguardar los derechos de sus ciudadanos y ciudadanas, la sociedad civil organizada retomaría cada vez más estas tareas, pero sin contar con espacios institucionalizados que le permitan asumir las nuevas tareas con eficacia. Las nucvas acciones en materia de defensa de derechos laborales pueden verse como una forma de la sociedad civil para auto procurarse aliados, instituciones y mecanismos alternativos de defensa de los derechos derivados de su condición de trabajadores o trabajadoras y, por tanto, como una forma de la politización de la misma sociedad civil y del mercado.

\section{8}

Realidad 90, 2002 
Las quejas sobre la capacidad del Estado para responder a los intereses de los trabajadores y las trabajadoras, no son nuevas en Centroamérica. Los sindicatos históricamente no han salido favorecidos en su relación con el Estado, los partidos políticos y otros actores institucionales. La diferencia es que la maquila se desenvuelve en un momento en el que en Centroamérica se han superado los conflictos bélicos resultados de regímenes autoritarios y se encuentra bajo sistemas democráticos de ejercicio del poder. En estos se supondría la apertura de espacios para la expresión ciudadana y para la interacción entre Estado y sociedad organizada y demandante. Empero, los espacios para la organización de los y las trabajadoras organizadas siguen siendo, en la práctica, proscritos. La naturaleza transnacional de la maquila ha abierto una ventana desde la cual se ofrecen otras opciones para la defensa de los derechos y para la regulación de las relaciones de trabajo y en este contexto, las debilidades de los Estados nacionales en garantizar los derechos ciudadanos son más perceptibles.

\section{Efectos y defectos de este modelo de acción social}

a) Resalta a la vista que es más rápido resolver los casos a través de la intervención de las marcas que a través de la acción estatal. Los escasos sindicatos independientes que existen en El Salvador, difícilmente se hubieran conseguido sin la intervención de Gap, Liz Claiborne, PVH o los estudiantes universitarios de los EEUU. Por otro lado, estas compañías se han encargado además, de presionar a sus clientes para resolver otros problemas laborales además de los sindicales propiamente, que procesados a través de las instancias estatales correspondientes hubieran demorado mucho tiempo y no habría certeza de que los fallos sean a favor del trabajador o trabajadora.

Pero, iqué pasa con las fábricas que trabajan para marcas menos famosas, o que no se van al mercado basándose en su imagen sino en sus bajos precios? ¿Qué pasa con las fábricas que dejan de trabajar para las marcas exigentes? El modelo no ofrece nada para ellas.

En un documento del Grupo de Monitoreo Independiente de El Salvador (GMIES) resalta como, mientras una compañía transnacional presionaba para hacer cambios en sus proveedores locales, las fábricas mejoraron notablemente en sus cumplimientos, pero una vez, esta marca cambia de proveedores, las fábricas se vinieron abajo en materia

\section{9}

Globalizando la occión social 
de cumplimiento a la legislación nacional, incluso por debajo de los niveles iniciales de las mismas, un año antes, cuando la investigación del GMIES dio inicio. Al parecer las fábricas no habian logrado hacer suyo el concepto de responsabilidad social y si mantuvieron cierta observancia sobre el mismo, era solamente para mantener un cliente, mas no para incorporarlo a su estrategia de negocios de manera permanente (GMIES, 2002).

No es difícil acusar a estas empresas de falta de visión empresarial. Es sabido que en maquila, al menos, las inversiones no están aseguradas a largo plazo. Las ventajas de las zonas francas serán eliminadas tarde o temprano en aras del llamado al libre comercio, promulgado por la Organización Mundial del Comercio (OMC). De hecho, los beneficios concedidos a estas empresas estaban por desaparecer a partir del 2005, pero gracias a un hábil cabildeo al interior de la OMC, en el 2001 se logró extender estas ventajas hasta el 2010, pero aun así, es claro que estos beneficios no lo serán para siempre. ¿Qué pasará una vez terminen? Las empresas deberán competir en el mercado internacional sin la ayuda de las ventajas arancelarias que ahora tienen en los países que las reciben y habrá que definir con base en qué las empresas centroamericanas se ganarán un lugar en el mercado.

Un empresario textil salvadoreño durante el pasado Encuentro Internacional de Responsabilidad Social Empresarial en mayo del 2002 dijo, muy analíticamente, que es muy difícil competir con base en bajos precios de producción. Siempre habrá algún país que ofrece mano de obra más barata y de hecho, con la incorporación de China a la OMC, la competencia sobre bajos precios será casi imposible para las empresas centroamericanas. La competencia podría basarse en otros asuntos, como dijo este empresario: la oferta de buenas condiciones de trabajo, que garanticen a los clientes de estas fábricas que sus productos serán elaborados con respeto a la normativa laboral, podría ser un incentivo para los clientes potenciales. Nadie quiere que su empresas aparezca en las campañas antisweatshop señalada por malas prácticas y el respeto a los derechos de los trabajadores podría ser un "plus" con que las maquilas de la región podrían competir.

Aun en este caso, el tema de los derechos laborales aparece como un tema de competitividad y no como un asunto de principios democráticos y siguen sin haber respuestas a las personas que trabajan para marcas que no se preocupan tanto por su imagen. 
b) Otra ventaja de este modelo de acción es que se obliga a las transnacionales a asumir algunas responsabilidades con el entorno en el que hacen negocios y se les presiona a responder por la situación de los trabajadores que elaboran sus productos. Estas empresas se han arrogado muchos derechos a lo largo de su existencia y cada vez reclaman mayores libertades para hacer sus negocios con el mínimo de responsabilidades. Los tratados de libre comercio, tan en boga hoy día, responden precisamente a esta situación. Además, los Estados mismos se encargan de facilitarle la entrada a los países del Sur y hasta subsidian de hecho, las actividades de estas grandes empresas, bajo la esperanza de captar inversiones y empleos que no se han podido crear en el entorno nacional.

El mero reconocimiento de que las empresas tienen responsabilidades y no sólo derechos, es un avance para la lucha por los derechos de los y las trabajadoras, pero, ¿qué posibilidades tiene este modelo para los y las trabajadoras que no están laborando para compañías multinacionales o que no están insertas dentro de las cadenas de producción global de mercancías? ¿Cuál es el efecto multiplicador de la responsabilidad corporativa de las grandes transnacionales, dentro de los espacios nacionales? $\mathrm{Al}$ parecer, no hay aún respuestas a estas interrogantes y nos pone en la mesa de discusión, una nueva debilidad de este nuevo estilo de reivindicaciones laborales.

c) El modelo requiere para su éxito de acciones conjuntas entre actores en el Norte y en el Sur. Nuevas formas de solidaridad transnacional son posibles, al parecer. Pero con estas nuevas relaciones es posible que surjan además, nuevas contradicciones. No ha resultado poco frecuente que las organizaciones centroamericanas se involucren en problemáticas que son propias del movimiento antisweatshop que está basado fundamentalmente en el Norte, o que al menos en la región, las dinámicas propias le daban un tratamiento diferente. Por ejemplo, el tema ONG-sindicato, siempre ha sido una dificultad en el Norte y en el Sur. Sin embargo, en Centroamérica el movimiento popular integró de alguna manera estas instancias y han logrado trabajar en conjunto sobre ciertos temas. En los EEUU la dinámica ONG-sindicato tiende a ser mucho más difícil. Con la llegada de organizaciones sindicales solidarias del norte, esta dificultad se ha introducido en la región y ha dificultado aún más, las acciones emprendidas. 
En Honduras, por ejemplo, las acciones del grupo de organizadores de una maquila, orientados por sindicatos de los EEUU chocaban fuertemente con las acciones de otras ONG vinculadas con la misma empresa. Las dificultades para la coordinación fueron aprovechadas por el dueño de la fábrica y en repetidas oportunidades, para distraer la atención de los problemas internos de la empresa, hacia los problemas que los organizadores sindicales le achacaban a la Ong. El único ganador de esta contienda resulto el dueño de la empresa que termino cerrando la fábrica y llevándose la inversión a otro país. No es que en Honduras no existieran previamente desencuentros entre las ONGs y los sindicatos, pero definitivamente, eran mucho más manejables antes de la llegada de los activistas estadounidenses (Quinteros, 2001).

Por otro lado, bajo esta construcción de nuevas redes es posible que se presenten tendencias a fomentar la dependencia de las organizaciones centroamericanas respecto a las organizaciones del Norte. Por un lado, es claro que las acciones de presión sobre el consumo no se realizan en Centroamérica, sino en los países donde se consume lo producido en el Sur y que por tanto, difícilmente se logrará alcanzar y responsabilizar a las marcas sin una acción en el Norte.

Las organizaciones del Norte no son refractarias a los intereses políticos. Ellas estarán dispuestas a contribuir a la causa de los trabajadores en el sur, en el momento en que estas concuerden con sus propios objetivos. ¿Qué pasa entonces si los trabajadores den el Sur quieren hacer una campaña sobre asuntos que no son de interés para los activistas en el Norte?, o bien ¿Si las quejas son sobre una fábrica que no trabaja para una compañía en la cual tengan interés en atacar los activistas en el Norte?

Todo ello sin dejar por fuera que las asimetrías entre unas y otras organizaciones podría jugar perversamente a favor de que las estrategias de reivindicaciones laborales para los y las trabajadoras centroamericanas se definan con base en los intereses de los activistas en el Norte.

Ciertamente, se construyen nuevas redes, pero, van a contribuir al mediano plazo en la formación de actores laborales fuertes en Centroamérica?

d) Finalmente, es interesante cómo se integra en la lucha al público consumidor. Antes de esto, los consumidores no veían en su acción 
nada más que una acción personalísima de escoger los productos y las marcas que mejor le quedaban. Sin embargo, las campañas que relacionan marcas con derechos laborales muestran el poder que el consumo puede tener en la defensa de los trabajadores en regiones remotas del Sur y se le otorga un valor político al mero acto de comprar. El consumo políticamente correcto se vuelve un tema de importancia para ciertos grupos de comparadores minoristas en los países del Norte.

Es sumamente difícil encontrar una marca que sea elaborada completamente "libre de explotación" y muy probablemente, al público en general solamente le llega la información de las marcas que no tienen campaña, que no es lo mismo a decir que no cometen violaciones a los derechos humanos. El consumidor o consumidora puede no caer en la cuenta que el consumo, aunque sea políticamente correcto es siempre consumo y podría generar asimismo, un consumismo "políticamente correcto".

\section{Conclusiones: ¿Puede el mercado sustituir al mercado en la de- fensa de derechos laborales?}

La respuesta obvia a esta interrogante es no. Los mecanismos de defensa laboral basados en mercado o en la responsabilidad empresarial, si bien, podrían conseguir resultados más rápidos en ciertas áreas sensibles, resultan ser sumamente vulnerables a los cambios en las relaciones comerciales, tienen poca oportunidad de reproducirse y multiplicarse al interior del país (aunque se hayan expandido claramente en los últimos años) y hacia otros sectores laborales no vinculados a las cadenas de producción global de mercancías y, encima de todo acarrean peligros para la misma autonomía de los actores laborales del Sur.

La resolución de casos laborales problemáticos, por muy exitosa que esta sea, si se ha realizado con base en la presión sobre relaciones comerciales para mantener un cliente o para evitar una campaña, siempre corren peligro de volatilizarse una vez, esa relación comercial deje de ser relevante para una de las partes.

Ciertamente, la frecuencia de institucionalidad en nuestros países y la poca seriedad con que nuestros Estados enfrentan los desafíos para el futuro de sus pueblos, no dejan otra salida que este tipo de arreglos 
eventuales y vulnerables. Pero el reto sigue siendo el mismo para las organizaciones laborales en El Salvador y en otro países del Sur: fortalecer el Estado de manera tal que sea capaz de ejercer su función de velar por los derechos de su ciudadanía trabajadora y que garantice el bienestar de la misma.

\section{Bibliografía}

Anner, Mark "The Dynamics and Unanticipated Outcomes of the AntiSweatshop Movement. Ponencia preparada para la XXII Congreso de Latin American Studies Association XXII International". Florida, Marzo, 2000.

ASEPROLA-CEDAL "El problema solidarista y la respuesta sindica en Centroamérica". Aseprola-Cedal, Heredia., 1989.

Bonacic Edna y Jill Esbenshade "Códigos de conducta y monitoreo en la industria de la confeccion de ropa en los EE.UU.". En Köpke, Molina y Quinteros (comp) "Códigos de conducta y monitoreo en la industria de la confección. Experiencias internacionales y regionales". Ediciones Heinrich Boll, San Salvador, marzo 2000.

Comité Nacional Laboral http://www.nlcnet.org. Consultada en Mayo, 2002.

Cordero, Allen 1999. "Actualización del estudio sobre la situación sociolaboral en las empresas maquiladoras del Istmo Centroamericano y Repuiblica Dominicana", OIT, San José, 1999.

Frank, Volker "Los códigos de conducta de Flores en Colombia”. En En Köpke, Molina y Quinteros (comp) "Códigos de conducta y monitoreo en la industria de la confección. Experiencias internacionales y regionales". Ediciones Heinrich Boll, San Salvador, marzo 2000.

Fortune Magazine http://www.fortune.com/lists/F 500/index.html. Consultada al 4 de junio del 2001.

Gereffi, Gary "Global Production systems and third world development". En Stallin Barbara, "Global change, regional response" Cambridge University Press, Cambridge, 1995

Gereffy, G; García-Johnson, R; Sasser, E. "The NGO-Industrial Complex". Foreing Policy, Washintong, july/august, 2001

GLEP, "Estrategias organizativas en la maquila" Mimeo. Guatemala, 1996

GMIES. www.gmies.org.sv. Consultada al 15 de julio, 2002. 
Keck, Margaret E. y Kathryn Sikkink. 1998. Activists Beyond Borders: Advocacy Networks in International Politics. Ithaca: Cornell University Press.

Klein, Naomi, "No Logo", Paidós Buenos Aires, 2001.

Maquila Solidarity Network www.web.net/ msn, Consultada en marzo 2001.

Pérez Sáinz, Juan Pablo: "Ciudadania social y derechos laborales en Centroamérica"._Cuaderno de Ciencias Sociales No. 108. FLACSO, San José 1998 (b).

Pérez Sáinz, Juan Pablo: "mercado laboral, integración y modernización globalizada en Centroamérica”. Nueva Sociedad, 164. Caracas, 1999.

Pineda, Magaly. "El caso de Levi Strauss en República Dominicana”. En Köpke et al. (comp) "Códigos de Conducta y Monitoreo en la Industria de la Confección. Experiencias internacionales y regionales." Fundación Böell, San Salvador, 2000.

Quinteros, Carolina, "Acciones y actores sindicales, para causas sindicales. El caso del monitoreo independiente en Centroamérica". Nueva Sociedad No. 169, Caracas, septiembre 2000.

Quinteros Carolina "Resistiendo creativamente. Actores y acción laboral en las maquilas de ropa en Centroamérica". FLACSO Costa Rica. San José, 2001. Próxima publicación

Trejos, María Eugenia Trejos y Mora, Minor "Entre el temor y la represión. Condiciones laborales y organizativas en la industria costamicense". Foro Sindical No. 4. Fundación Friedrich Ebert. San José.

NOTAS

1. Nombre con que se le conoce al movimiento de activistas en contra de las "explotación en las maquilas".

2. Posteriormente, los medios dieron a conocer que el verdadero boicot a las negociaciones de la ICC provenia más bien de personas del Congreso de los FEUU. El Senador Helms, cercano al Presidente Bush, promovía medidas para limitar el aceeso de exportaciones de telas (aunque de origen estadounidense) tratadas y/o cortadas en los países de la ICC.

3. Por independientes, entenderemos aqui que son sindicatos no formados a instancias de la empresa.

4. Al respecto, Magali Pineda del CIPAF" manifiesta que: “...creo que el reconocimiento de la dificultad de la organización sindical es lo que ha hecho que muchas ONG hayamos empezado a reaccionar al tema del debate de los códigos de conducta, con más simpatía que lo que han reaccionado los sindicatos. ¿lor qué? Porque muchos de nosotros pensamos que cualquier esfuerzo que tenga como fin mejorar las condiciones de trabajo de la gente y ascgurar un trabajo digno, debe 
hacerse. Es indudable que si este trabajo se logra a través de un proceso organizativo, empoderaria a los trabajadores. Pero tampoco podemos rechazar que esas mejoras puedan llegar por otras vías. No podemos rechazarlas simplemente porque no llegan por la vía de la organización sindical. (Pineda, 2001)

5. Una acrivista dominicana manifiesta lo siguiente: "He trabajado en las zonas de libre comercio por más de 30 años y hasta el año pasado tenía el sentimiento de que nada cambiaba realmente. Hace dos años participé en un proyecto piloto cn Levi Strauss, el cual abarcó a sus cuatro contratistas principales en la República Dominicana. Lo que vimos es como la presión de una transnacional producía un cambio positivo para las trabajadoras en un perído de cuatro años.... Quizás en otros países los códigos (de conducta) no funcionen, pero en estas cuatro fábricas tuvo un impacto positivo en la vida de todas las mujeres que trabajan allí." (AMRC, 1999)

6. Discurso ante la Asociación Nacional de Anunciantes, citado en The New York Times 20 de octubre de 1997. (Klein, 2001, p. 47-48). 